\title{
Investigation of the Effect of Compaction on the Anaerobic Digestion Process
}

\section{Guangyin Chen ( $\nabla$ xzcf2004@163.com )}

Anhui Normal University

\section{Hai-Nan Cao}

Anhui Normal University

Xue-Qian Fan

Anhui Normal University

Yi-Chen Sun

Anhui Normal University

Jing Wang

Anhui Normal University

Jingzhu Dong

Anhui Normal University

\section{Pei Wu}

Anhui Normal University

\section{Research Article}

Keywords: anaerobic digestion, compaction, rice straw, biogas production

Posted Date: August 4th, 2021

DOl: https://doi.org/10.21203/rs.3.rs-743267/v1

License: (c) (i) This work is licensed under a Creative Commons Attribution 4.0 International License.

Read Full License 
1 Investigation of the effect of compaction on the anaerobic 2 digestion process

3 Guang-Yin Chen ${ }^{\text {a, b }}$, Hai-Nan Cao ${ }^{\text {b }}$, Xue-Qian Fan ${ }^{\text {b }}$, Yi-Chen Sun ${ }^{\text {b }}$, Jing-Wang ${ }^{\text {b }}$, Jin-

4 Zhu Dong ${ }^{\mathrm{b}}$, Pei-Wu ${ }^{\mathrm{b}}$

5 a. Anhui Engineering Laboratory of Soil and Water Pollution Control and Remediation;

6 b. School of Ecology and Environment, Anhui Normal University, Wuhu 241002, China 


\section{Abstract}

This paper aims to evaluate the effects of compaction on the anaerobic biodegradability of straw. In the study, compaction tests were carried out at different applied pressures, i.e., 0 (CK), 277 (T1), 555 (T2), and $1109 \mathrm{~Pa}$ (T3), respectively. The changes in physicochemical indicators (i.e., pH, VFA, COD, and DHA) of the liquid digestate were monitored. Factor analysis was adopted to analyze biogas production's main factors in the bath Anaerobic digestion (AD) process. Changes in the surface structures and composition of solid digestate were analyzed. The results showed that the maximum gain in biogas production was $298.35 \mathrm{~mL} \cdot \mathrm{g}^{-1} \mathrm{TS}$ for the $\mathrm{T} 2$ reactor, significantly higher than that of $\mathrm{CK}$ and $\mathrm{T} 3$ reactors. The effect of compaction on the physicochemical index of liquid digestate was not significant during the batch-type AD process. The factor analysis results suggested that the major factors affecting biogas production were influenced by the compaction and varied based on the different stages of digestion. Scanning electron microscopy (SEM) showed that the straw surface was damaged as the compaction increases; however, the degree of damage was not significant. This research concluded that compaction on gas production via changing the environment during the bath $\mathrm{AD}$ process and proper compaction could positively affect biogas' yield, while excessive compaction will inhibit gas production.

Keywords: anaerobic digestion, compaction, rice straw, biogas production 


\section{Introduction}

China has abundant agricultural straw resources, with about 560 million tons [1]. Anaerobic digestion (AD) is a proven and stable technology and primarily produces a high energy recovery from agricultural waste and has been considered the leading commercial option [2-3]. By converting straw into biogas, liquid, and solid digestate through this technology, the recycling of straw carbon and nitrogen resources is achieved, which is in line with the development requirements of circular agriculture. Batch type $\mathrm{AD}$ process is a form of anaerobic digestion with the advantages of simple operation and reduced labor management costs. Many centralized gas supply projects with straw as the primary raw material have been built in rural areas of China, and most of these projects are based on the batch-type AD process [4]

However, during the batch type AD process, the straw was subject to buoyancy, gravity, the upward force of the generated biogas, coupled with many factors such as the decline in mechanical strength of straw due to material decomposition, causing the straw to squeeze each other. This will inevitably lead to straw porosity reduction, tightness increase, and crusting more serious, ultimately affecting biogas production from straw. Meanwhile, the leachate reflux will be limited during the straw batch type AD process. However, it has to be noted that leachate circulation within the substrate serves as a transport medium for heat, nutrients, and material exchange inside the digester [5]. Furthermore, it is essential to enhance leachate reflux for biogas production due to the difficulty of mixing in the batch-type AD process. Rocamora et al. [6] also mentioned that batch $\mathrm{AD}$ was affected by factors like micro and macroporosity, the 
degree of compaction or the material's permeability to be digested. On this note, it is necessary to investigate the effect of compaction on the batch-type AD process. Nevertheless, only very little research in the literature has been performed in connection with this field. In a study conducted by Wedwitschka et al. [5], material compaction occurred during the digestion process and can have a negative effect on substrate permeability. André et al. [7] observed a slight decrease of the manure porosity, and presumably, it was caused by compaction on the batch $\mathrm{AD}$ during the recirculation of percolate. Wedwitschka et al. [8] found that compressive forces impacted the permeability and resulted in compression of the material tested through matrix substrate characterization experiments of an anaerobic batch digestion system. The above studies mainly focused on the changes in the physical properties of the substrates by compaction during the batch-type AD process. However, the exact effect of different compaction levels on the batch type AD process is not apparent.

The objective of this study was to make a step forward to understanding the effect of compaction during the batch-type AD process. Different compaction levels were set based on batch $\mathrm{AD}$ experiments at the lab scale in the present study. The impacts of compaction on the physicochemical indexes of the liquid digestate, structural and compositional changes of solid digestate, and biogas yield were comprehensively investigated and compared.

\section{Materials and methods}

\section{Feedstock and Inoculum}

Rice straw was harvested in local fields in Jiangsu, China. Rice straw was dry and 
chopped manually to a size of about 2 to 3 centimeters, then set aside in a dry and cool place. The inoculum was activated sludge taken from wastewater treatment plants acclimated and cultured at $(37 \pm 1){ }^{\circ} \mathrm{C}$ with pig manure for 20 days. The inoculum stops adding substrate one week before AD. The primary physicochemical properties of straw and inoculum are shown in Table 1.

\section{Anaerobic digestion reactor}

A digestion experiment was conducted using the 5-L reactor. The reactor was made of clear cylindrical acrylic with a diameter of $16 \mathrm{~cm}$ and $28 \mathrm{~cm}$ in height. The hot water in the thermostat water bath was pumped into the jacket of the reactor for heating. An air vent was arranged at the top of the fermenter, and the biogas produced enters the gas collecting bag through the outlet. The digestive fluid was collected through the outlet at the bottom of the reactor. The anaerobic digestion unit is shown in Fig 1.

\section{Compaction experimental design}

Four different masses of weights were used, i.e., $0 \mathrm{~g}, 500 \mathrm{~g}, 1000 \mathrm{~g}$, and $2000 \mathrm{~g}$, respectively, and the corresponding pressures are 0, 277, 555, and $1109 \mathrm{~Pa}$. Weights were placed at the top of the straw pile, which simulated compaction that occurs in the batch type AD process. The treatment group with the pressure of 0, 277, 555, and 1109 Pa was denoted as CK, T1, T2, and T3 groups. A known weight of the porous round plate, with a size and aperture of 14 diameters and $3 \mathrm{~mm}$, respectively, was put on the straw pile to bear different weights and ensure uniform force on the straw in the reactor. Prepared $300 \mathrm{~g}$ of straw (based on the dry matter) was subjected to an anaerobic 
test, and $1.5 \mathrm{~L}$ inoculum was mixed into the reactors and then added $1.2 \mathrm{~L}$ distilled water to ensure TS concentration was $10 \%$. The substrate/inoculum (S/I) ratio was 10.15 (based on volatile solids (VS)). During the experiment, the liquid digestate was returned from the bottom to the top of the digester every day. To ensure that the digestive solution flowed back into the straw pile evenly, two layers of gauze were placed between the straw pile and the porous circular plate. Three replicates of each treatment group were carried out in the batch-type $\mathrm{AD}$ process. The reactor was sealed at a controlled temperature of $(37 \pm 1){ }^{\circ} \mathrm{C}$ using a thermostat water bath. The main performance parameters, including $\mathrm{pH}$ value, chemical oxygen demand (COD), total volatile fatty acids (VFA) content, and dehydrogenase activity (DHA), were monitored on the 0,2 , $5,9,14,20,30$, and $45 \mathrm{~d}$ of the experiment, respectively.

\section{Analytical methods}

The $\mathrm{pH}$ value was determined using a $\mathrm{pH}$ meter (Mettler Toledo, Switzerland); total solids (TS), volatile solids (VS), total Kjeldahl nitrogen (TKN), total organic carbon, and COD were determined according to APHA's Standard Methods [9]; Total volatile fatty acids (TVFA) were measured according to Zou et al. [10]; The lignin, cellulose, and hemicellulose contents were determined according to the procedures proposed by Van Soest et al. [11]; The dehydrogenase activity (DHA) was determined based on the reduction of 2,3,5-triphenyl tetrazolium chloride (TTC), as described by Zhou et al. [12]. The external surface of straw with different compaction levels was observed using a scanning electron microscope (SEM) (S3400, Hitachi, Japan) at an acceleration voltage of $20 \mathrm{kV}$. The degradation of TS, cellulose, hemicellulose of 
feedstock during AD was analyzed and calculated as earlier described [13], according to Eq. (1):

\section{Degradation rate $(\%)=(Y-C) / Y \times 100 \%$}

where $\mathrm{Y}(\mathrm{g})$ is the initial amount of a component in the raw straw and $\mathrm{C}(\mathrm{g})$ is the final amount of a component in the digestate at the end of the experiment.

\section{Factor analysis}

Factor analysis is a multivariate statistical technique used to finding theoretical concepts that underlie the association between observed variables. It explores the underlying structure in the observed data by examining the internal dependencies among many variables and representing their underlying data structure with a few dummy variables. These few dummy variables can reflect the primary information of the numerous original variables $[10,14]$. The mathematical model for factor analysis, as follows.

$$
\left(\begin{array}{c}
x_{1} \\
x_{2} \\
\vdots \\
x_{p}
\end{array}\right)=\left(\begin{array}{c}
\mu_{1} \\
\mu_{2} \\
\vdots \\
\mu_{p}
\end{array}\right)+\left(\begin{array}{cccc}
\alpha_{11} & \alpha_{12} & \cdots & \alpha_{1 m} \\
\alpha_{21} & \alpha_{22} & \cdots & \alpha_{2 m} \\
\cdots & \cdots & \ddots & \cdots \\
\alpha_{p 1} & \alpha_{p 2} & \cdots & \alpha_{p m}
\end{array}\right)\left(\begin{array}{c}
F_{1} \\
F_{2} \\
\vdots \\
F_{p}
\end{array}\right)+\left(\begin{array}{c}
\xi_{1} \\
\xi_{2} \\
\vdots \\
\xi_{p}
\end{array}\right)
$$

Abbreviated as:

$$
x_{p}=\mu_{p}+\alpha_{11} F_{1}+\cdots \alpha_{p m} F_{p}+\xi_{p}
$$

where the $F_{p}, \mathrm{p}=1, \ldots, \mathrm{k}$, are $\mathrm{k} \geq 1$ random variables called factors, $\mathrm{X}=\left(x_{1}\right.$, $\left.x_{2}, \ldots, x_{3}\right)^{\mathrm{T}}$ is an observable random variable, $\mathrm{F}=\left(F_{1}, F_{2}, \ldots, F_{p}\right)^{\mathrm{T}}$ is a common factor (factors), $\xi=\left(\xi_{1}, \xi_{2}, \ldots, \xi_{p}\right)^{\mathrm{T}}$ is the special factor, $\mathrm{F}$ and $\xi \quad$ are not observed random variables, $\mu_{p}=\left(\mu_{1}, \mu_{2} \ldots, \mu_{3}\right)$ is the ensemble average of random variable $\mathrm{X}$. Thus, $\mathrm{X}$ is standardized, and the ensemble average of the standard variable is ' 0 ,' and the 
variance is ' 1 '. This is represented as follows:

$$
\left(\begin{array}{c}
x_{1} \\
x_{2} \\
\vdots \\
x_{p}
\end{array}\right)=\left(\begin{array}{cccc}
\alpha_{11} & \alpha_{12} & \cdots & \alpha_{1 m} \\
\alpha_{21} & \alpha_{22} & \cdots & \alpha_{2 m} \\
\cdots & \cdots & \ddots & \cdots \\
\alpha_{p 1} & \alpha_{p 2} & \cdots & \alpha_{p m}
\end{array}\right)\left(\begin{array}{c}
F_{1} \\
F_{2} \\
\vdots \\
F_{p}
\end{array}\right)+\left(\begin{array}{c}
\xi_{1} \\
\xi_{2} \\
\vdots \\
\xi_{p}
\end{array}\right)
$$

Abbreviated as:

$$
x_{p}=\alpha_{p m} F_{p}+\xi_{p}
$$

If

(1) $\mathrm{E}\left(F_{p}\right)=0, \delta\left(F_{p}\right)=1$.

(2) $\mathrm{E}\left(\xi_{p}\right)=0, \delta\left(\xi_{p}\right)=\xi_{p}$.

(3) $F_{p}$ and $\xi_{p}$ mutual independence

Thus, $\mathrm{X}$ is a factor model which has a common factor. There were four variables in the model, namely $\mathrm{pH}$, VFA, COD, and DHA content. The factor analysis was to obtain the main factors influencing the biogas yield in different digestion stages and compaction.

\section{Calculations and statistical analyses}

One-way ANOVA $(\mathrm{p}<0.05)$ and factor analysis were carried out with the software package SPSS, version 21. Origin Lab program was used for plotting. All data shown are the average values of independent triplicates $(n=3) \pm S D$.

\section{Results and discussion}

\section{Effect of compaction on the physicochemical index of liquid digestate}

\section{Influence on the pH value and VFA content}

The $\mathrm{pH}$ value is one of the indicators of the stability of the anaerobic digestion 
system, reflecting the buffer capacity of the system. The changes in $\mathrm{pH}$ value under different pressures during the experiment can easily be observed from the results depicted in Fig. 2(a). For all runs, the trends of $\mathrm{pH}$ values change of experiments were similar, but with some differences. For the initial stage of $\mathrm{AD}$, the $\mathrm{pH}$ values had dropped considerably. After that, it recovered and rose to reach the original level and finally stabilized. There were some notable differences in $\mathrm{pH}$ changes as a result of different pressures. The lowest $\mathrm{pH}$ values of $\mathrm{CK}$ and $\mathrm{T} 1$ reactor were observed on the second day, while it can also be noted that the gain in lowest value of $\mathrm{pH}$ for $\mathrm{T} 2$ and $\mathrm{T} 3$ reactors during digestion on day five. The lowest $\mathrm{pH}$ over the whole anaerobic digestion process at the different groups: $6.94,6.78,6.69$, and 6.36 for $\mathrm{CK}, \mathrm{T} 1, \mathrm{~T} 2$, and $\mathrm{T} 3$ reactors. $\mathrm{pH}$ had dropped considerably during the first five days can be ascribed that the rate of acidogenesis, a conversion of soluble organics to VFAs, is typically much faster than methanogenesis in an anaerobic environment. VFAs could not be utilized by methanogens adapted to the environment slowly and weak metabolic capacity, resulting in the accumulation of fatty acids [15]. Thus, this phenomenon is inevitable. It is also noticed in Fig. 2(a) that the CK reactor obtained the highest $\mathrm{pH}$ value, followed by $\mathrm{T} 1$, $\mathrm{T} 2$, and $\mathrm{T} 3$ reactors during the first nine days. It suggested a significant decrease in the specific $\mathrm{pH}$ value within the more considerable pressure acting on the straw. This phenomenon may be due to the floating of the straw in the CK group in this study, resulting in insufficient contact with the inoculum. The pressure is a factor leading to good contact with straw and inoculum, and the more organic matter that undergoes hydrolysis, the more volatile fatty acids, which may lead to system acidification. $\mathrm{pH}$ 
value, therefore, goes down as the pressure increases. The $\mathrm{pH}$ values of all digesters were within an ideal range for $\mathrm{AD}$, i.e., $4.0-8.5$ for fermentative bacteria and 6.8-7.4 for methanogens [16-17].

In addition to $\mathrm{pH}$ measurement, VFA was determined since $\mathrm{pH}$ is not a sole indicator of $\mathrm{AD}$ failure [18]. The analysis of VFA production provides valuable information on the evolution of the AD process. VFA concentration is one of the most critical parameters to indicate process stability during anaerobic digestion, and its initial content is known to affect the $\mathrm{CH}_{4}$ generation yield [19-20]. Acid-producing bacteria degraded organic matter to produce VFA, resulting in a decrease of $\mathrm{pH}$, and in this study, $\mathrm{pH}$ changes corresponded well with the VFA concentration (Fig. 2b). VFA concentration increased in the first five days and reached the highest level on the 5th day. This phenomenon was typical for the start-up stage of $\mathrm{AD}$ because of the unbalance among hydrolytic, acetogenic, and methanogenic functions during this period [21]. Meanwhile, peak values, starting time, and peak appearance times were similar during AD. The highest concentrations of VFA were detected in digested slurry from all reactors, with $11.62 \mathrm{~g} / \mathrm{L}$ for $\mathrm{T} 3$, and with $9.28 、 10.68 、 10.64 \mathrm{~g} / \mathrm{L}$ for $\mathrm{CK}, \mathrm{T} 1$, and $\mathrm{T} 2$ reactors, respectively. Furthermore, VFA concentration of CK, T1, T2, and T3 groups on day 9 obtained significant deteriorations of $6.38,6.33,6.45$, and $5.04 \mathrm{~g} / \mathrm{L}$, respectively, compared with day five. The consumption of VFA in the T3 reactor was the lowest. The results showed that acidification was most severe in the T3 reactor and that methanogenic activity was easily inhibited during the AD process, which was consistent with the biogas yield of the subsequent $\mathrm{AD}$ process. The stage of rapid 
acidification in all reactors reached its peak need only five days, and then the VFA was consumed heavily with the increase of biogas production. Thus, the VFA value decreases rapidly.

\section{Influence on the COD and DHA content}

The utilization of COD was monitored in all anaerobic digester set-ups, reflecting the utilization of organic matter in an anaerobic system. It was found that all reactors under different pressure during the whole $\mathrm{AD}$ process for $\mathrm{COD}$ concentration showed a noticeable trend of the first increase, then decrease, and finally stabilize, as shown in Figure. 3(a). The refractory macromolecular organic matter was decomposed by specific microorganisms, i.e., acid-forming bacteria, during the hydrolytic acidification phase, reaching maximum COD concentrations of 33.39, 38.30, 37.54, and $39.12 \mathrm{~g} / \mathrm{L}$ in the reactor of $\mathrm{CK}, \mathrm{T} 1, \mathrm{~T} 2$, and $\mathrm{T} 3$, respectively. After then, small molecular organic matter was decomposed into digestive juices, as a proper archaeal population (mainly composed of Methanosarcina) was developed and became the dominant bacteria [22]. It also can be observed that COD content in this study remained between 14.56$18.03 \mathrm{~g} / \mathrm{L}$ for each treatment during the stabilization phase (among the days 20 and 49). Higher COD content was hardly obtained in this phase due to organic macromolecules in digestive juices have been fully degraded. The COD concentrations of CK, T1, T2, and $\mathrm{T} 3$ reactor were determined to be $15.93,14.56,16.69$, and $16.91 \mathrm{~g} / \mathrm{L}$, respectively, at the end of $\mathrm{AD}$. It was noteworthy that the $\mathrm{COD}$ concentration of the $\mathrm{T} 3$ reactor was higher than the initial value, which was detected as $15.49 \mathrm{~g} / \mathrm{L}$. This phenomenon may be caused by higher compaction and acidification of the system, where microbial 
activity was inhibited, and more soluble compounds were not utilized.

The DHA reflects the level of microbial activity during the AD process, which can be used as an indirect indicator responding to the microbial quantity [22]. As an intracellular enzyme, dehydrogenase is required by microorganisms to degrade organic molecules and obtain energy [23]. The changes in the DHA levels are shown in Figure. 3(b), which demonstrates that the activity levels first increased and decreased gradually during AD. The changing trend was consistent with that of VFA and COD concentration. During the first nine days, the differences in DHA among all treatments were not significant. The maximum values of DHA for the $\mathrm{CK}, \mathrm{T} 1, \mathrm{~T} 2$, and $\mathrm{T} 3$ reactors were obtained on the second day with $26.11,28.09,29.94$, and 31.97 ug TPF/ (h mL), respectively. There was adequate preparation of the dehydrogenation reaction at the beginning of $\mathrm{AD}$, which reaches maximum value time was four days shorter than that of [24]. As the organic matter in the digester was consumed and sufficient nutrients cannot be provided for microbial growth and reproduction, the DHA began to decline. Among the days 9 and 49, the main argument used for the higher DHA with increased pressure may be because more straw was immersed under pressure into the digestive juices, bringing it into contact with more microorganisms. Therefore, the T3 reactor was the highest of all the digesters.

\section{Factor analysis}

Factor analysis can explore the relationship between daily gas production and environmental factors in $\mathrm{AD}$ [10]. Thus, factor analysis was used to analyze the influence of the $\mathrm{pH}$ value, COD, VFA, and DHA content on daily biogas production 
between the CK and T3 groups. Factor analysis suitability test results showed that the significant probability of Bartlett's spherical test was less than 0.01 for both CK and T3 groups, and the KMO test values were 0.581 and 0.545 , respectively, which were greater than 0.5 , and hence factor analysis could be used.

The results of the total ANOVA in the factor analysis showed that all treatments explained $91.06 \%$ and $97.15 \%$ of the information on $\mathrm{pH}$ value, COD, VFA, and DHA content with two common factors (factor 1 and factor 2). The factor loading matrix coefficients can be used to indicate the dependence of the factors on the indicators. The larger the absolute value, indicated a higher determination coefficient of the factors on the index., and also the importance of the factors on the indicators [14]. As shown in Table 2, the absolute values of the loading coefficients for factor 1 of CK were 0.96 (COD), 0.76 (VFA), and 0.63 (DHA), and these were greater than the absolute values of the corresponding loading coefficients for these variables for factor 2 . The absolute value of the loading coefficient on factor 2 of $\mathrm{CK}$ was $0.95(\mathrm{pH})$, which was greater than the absolute value of the corresponding loading coefficient of this variable for factor 1 . This means that factor 1 of $\mathrm{CK}$ was determined by COD, VFA, and DHA content, and factor 2 of $\mathrm{CK}$ was determined by $\mathrm{pH}$ value. However, factor 1 of T3 was determined by $\mathrm{pH}, \mathrm{COD}$, and VFA content, while factor 2 was determined by DHA. Table 2 indicated that the primary factors and the daily biogas production were affected by compaction. Research has shown that pH value [17], COD content [22], VFA content [19], and DHA [23] affected biogas production, and these were consistent with the results of the present study. 

digestion process on days $0,2,5,9,14,20,30$, and 49 were $0.39,0.35,1.65,0.85$, $0.11,-0.93,-1.05$, and -1.14 , respectively, while the scores of factor 2 in CK were -1.73 , $1.59,0.73,-0.56,-0.66,0.02,0.30$, and 0.31 . The factor that scored higher also indicates that a higher correlation at the same time with daily biogas production [10]. Thus, combined with Table 2 (factor 1 of CK was determined by COD, VFA, and DHA content and factor 2 was determined by $\mathrm{pH}$ ), it was concluded that daily biogas production was influenced greatly by COD, VFA, and DHA content on days $0,5,9$ and 14 and that the daily biogas production was influenced greatly by $\mathrm{pH}$ value on days 2 and late in the reaction. This was in accordance with the findings of Zou et al. [25]. content and factor 2 was determined by $\mathrm{DHA}$ ), it was concluded that $\mathrm{pH}, \mathrm{COD}$, and VFA content had the most influence on days 5, 9, and 49, while the DHA had the maximum influence on days $0,2,14,20$ and 30 . The combined analysis of CK and T3 impression on the main influencing factors of daily gas production during AD. And finally, the combined factor scores were calculated (Table 3), the result revealed that the top four of CK and T3 reactor scores were identical, all occurring on days 5, 2, 9, and 14. It indicated that these days had the greatest effect on gas production and was verified from the daily gas production graph. 
The effects of the compaction on the straw surface characterization changes during batch AD process were studied by SEM, using the most severe pressure, i.e., T3 reactor sample, compared with the uncompacted straw, as shown in Fig. 4. It was depicted that the surface of straw was damaged during $\mathrm{AD}$, and the texture was unordered and fragmented. In general, however, the straw surface damage degree was not particularly serious, and some holes also did not appear on the surface of solids; this is ascribed to native straw is covered by a silica layer that prevents enzymatic hydrolysis [26]. After $\mathrm{AD}$, the available organic matter for microbes was completely utilized, and the rest of the structure appeared rigid, which could not be degraded by microbes in AD [21]. little effect on the extent of straw structure destruction during batch type AD process.

\section{The influence on the composition}

In terms of anaerobic biodegradability, straw can be divided into nonbiodegradable substances and biodegradable substances, which mainly consist of cellulose, hemicellulose, lignin, and other non-structural components, called extractives [2,27]. TS, cellulose, and hemicellulose content will be reduced accordingly during AD. Thus, the removal rate of TS, cellulose, and hemicellulose can reflect the consumption of substances in the $\mathrm{AD}$ for biogas production. rate of TS, cellulose, and hemicellulose during the 49-day AD of different pressure of 
straw is presented in Fig. 5. As is shown, there was a significant decrease in the cellulose and hemicellulose contents of the straw (Fig. 5a). The cellulose content of $28.64 \%$ in raw straw was decreased to $15.58 \%, 9.65 \%, 11.68 \%, 13.92 \%$ for CK, T1, T2, T3 group, respectively, the corresponding ranges for hemicellulose were from $24.47 \%$ in the raw straw to $17.14 \%, 18.82 \%, 15.95 \%, 18.80 \%$, respectively. It should be noticed that hemicellulose can be utilized for methane production. Interestingly, it acts as a physical

barrier, preventing the accessibility of hydrolytic enzymes and microorganisms to cellulose [26]. An increase in the percentage of lignin was observed; it was reasonably due to a decrease in cellulose and hemicellulose content. During AD, the total lignin had a slight change, and it being a practically non-biodegradable compound by anaerobic microorganisms [28]. The highest decrease in cellulose percentage composition was observed for the $\mathrm{T} 1$ reactor; accordingly, the highest cellulose degradation of $69.40 \%$ was observed during $\mathrm{AD}$ (Fig. 5b). It is also noticed that the higher the pressure applied, the lower the cellulose loss. The main argument may be that the compaction production caused the straw to be more compacted and the microorganisms to be more difficult to degrade. Upon inspection of Fig. 5b, we can also clearly see that degradation of TS in the AD did correlate to biogas yield, the best performance of TS loss rate was T2 (44.79\%), followed by the T1 (43.61\%) and T3 (41.91\%), and the lowest was CK (37.64\%).

\section{Effect of compaction on biogas production}

The daily biogas production and accumulative biogas yield over the 49-d's test period at different reactors are displayed in Fig. 6. Fig. 6a shows that the daily biogas 
production in all reactors experienced significant fluctuations, while the fluctuation of daily biogas yield is a common phenomenon during the initial period of $\mathrm{AD}$ of lignocellulosic materials due to acidification [29]. When most of the material was consumed, the daily biogas production declines and maintained a low level after 30 days of incubation. Initially, as can be seen, biogas was generated from the day after inoculation. However, the biogas yield was low at the start-up stage of the experiment could be attributed to the inhibitory effects of by-products, e.g., VFAs, which can cause an imbalance among hydrolysis, acidogenesis, acetogenesis, and methanogenesis reactions, and the activity of methanogenic bacteria [30]. Methanogens then adapt quickly, and biogas production gradually increased. Considering the daily biogas production, $\mathrm{T} 2$ reactor, a maximum of $16.57 \mathrm{~mL} \cdot \mathrm{g}^{-1} \mathrm{TS}$ was attained on day 5 , while the highest production yield $\left(11.17 \mathrm{~mL} \cdot \mathrm{g}^{-1} \mathrm{TS}\right)$ was observed at $\mathrm{T} 3$ digester until day 10 , which was five days late. For CK and T1 reactor, the maximum daily biogas production was15.35 and $15.07 \mathrm{~mL} \cdot \mathrm{g}^{-1} \mathrm{TS}$ on days 6 and 8 , respectively. Two obvious peaks of daily biogas appeared during $\mathrm{AD}$ for all cases. Note that the peak values, starting time, and peak appearance times were different. Peak one may be derived from the methane conversion of pre-existing SCOD in the feedstock, while peak two represented the further solubilization of tightly bound biodegradable substances and even some of the hard-to-degrade biodegradable compounds [31].

Based on Fig. 6(b) information, it was significant that differences in biogas accumulation existed between reactors. The effect of cumulation biogas was, as expected, related to the external pressure applied. Again, the highest biogas 
accumulation was for the $\mathrm{T} 2$ digester, followed by $\mathrm{T} 1, \mathrm{~T} 3$, and CK reactor, with 298.35, $291.54,249.14,228.51 \mathrm{~mL} \cdot \mathrm{g}^{-1} \mathrm{TS}$, respectively. For T2 reactor, causing significant $(p<$ 0.05 ) improvement of $23.41 \%, 16.49 \%$, respectively, compared with CK, T3 reactors. However, the cumulative biogas yield of the T2 reactor no significantly $(p>0.05)$ improved 2.28\%, compared with the $\mathrm{T} 1$ reactor. Further to this, no significant difference $(p>0.05)$ was acquired between the cumulative biogas yields from the T3 reactor and CK. The result indicated that biogas production could be increased when external pressure was applied to the reactor. However, there was no remarkable effect when the external pressure was too high. Further investigation on this issue was worth exploring to evaluate the maximum compaction inside the digester that will restrict biogas production.

Combined with Figure. 2, 3,4, and Figure. 6, it should also be worth mentioning that, in this study, compared to other reactors, the concentration of COD and TVFA of T3 reactor was the highest, same thing for DHA, while the peak time of daily gas production was delayed and the cumulative biogas production was also significantly lower. It can likely be ascribed to the following reasons: (1) The decomposition of substances in rice straw led to a decrease in mechanical strength, causing the straws to crush each other. Stress conditions of straw in digester were further investigated; The straw was subjected to four forces inside the reactor, that is, gravity, the pressure generated by the upper straw pile, support force, and thrust generated by biogas. However, these four forces interact with each other in the AD process and, causing a decrease in straw porosity and the straw surface to denser. As a result, the biogas 


\section{Conclusions}



pressure to simulate the compaction of the digester. The highest total biogas production was for the $\mathrm{T} 2$ digester with $298.35 \mathrm{~mL} \cdot \mathrm{g}^{-1} \mathrm{TS}$, which was significantly higher than the CK (68.55 L). The pH value, COD, VFA, and DHA content in the digester and their maximum and the minimum value in the $\mathrm{AD}$ process were not significantly influenced by compaction. The main factors affecting biogas production were different at varying degrees of compaction; however, the main stages affecting gas production were the same. Compaction has little effect on the extent of straw structure destruction during batch type $\mathrm{AD}$ process. (1808085ME132). study are available from the corresponding author on reasonable request.

\section{Author contribution}

1. Guang-Yin Chen: Conceptualization, Methodology, Supervision, Funding acquisition.

2. Hai-Nan Cao: Formal analysis, Investigation, Writing- Original Draft, Visualization.

3. Xue-Qian Fan: Resources, Investigation. 
4. Yi-Chen Sun: Resources, Investigation.

5. Jing-Wang: Resources, Investigation.

419 6. Jin-Zhu Dong: Writing - Review \& Editing.

420 7. Pei-Wu: Writing - Review \& Editing.

\section{Declarations}

422 Ethics Approval Not applicable.

423 Consent to Participate Written informed consent for publication was obtained from

424 all participants.

425 Consent for Publication All the authors consent to publication.

426 Conflict of Interest The authors declare no competing interests. 


\section{References}

433

1. Cai YF, Zheng ZH, Schafer F, Stinner W, Yuan XF, Wang HL, Cui ZJ, Wang XF (2021) A review about pretreatment of lignocellulosic biomass in anaerobic digestion: Achievement and challenge in Germany and China. J Clean Prod 299: 126885. https://doi.org/10.1016/j.jclepro.2021.126885

2. Zhang YL, Chen XH, Gu Y, Zhou, XF (2015) A physicochemical method $\mathrm{f}$ or increasing methane production from rice straw: Extrusion combined with alkali pretreatment. Appl Energ 160: 39-48. https://doi.org/10.1016/j.apenergy. 2015.09.011

3. Forster-Carneiro T, Perez M, Romero LI, Sales D (2007) Dry-thermophilic anaerobic digestion of organic fraction of the municipal solid waste: Focusi ng on the inoculum source. Bioresource Technol 98: 3195-3203. https://doi.o rg/10.1016/j.biortech.2006.07.008

4. Yang Q, Ju MT, Li WZ (2016) Review of methane production from straws anaerobic digestion. Transactions of the CSAE 32(14): 232-242. https://doi. org/10.11975/j.issn.1002-6819.2016.14.031

5. Wedwitschka H, Gallegos D, Tietze M, Reinhold J, Jenson E, Liebetrau J, Nelles M (2020) Effect of substrate characteristics and process fluid percola tion on dry anaerobic digestion processes. Chem Eng Technol 43 (1): 59-67. https://doi.org/10.1002/ceat.201900404

6. Rocamora I, Wagland ST, Villa R, Simpson EW, Fernandez O, Bajon-Fernandez Y (2020) Dry anaerobic digestion of organic waste: A review of operational 
parameters and their impact on process performance. Bioresource Techno 299: 122681. https://doi.org/10.1016/j.biortech.2019.122681

7. Andre L, Durante M, Pauss A, Lespinard O, Ribeiro T, Lamy E (2015) Quantifying physical structure changes and non-uniform water flow in cattle manure during dry anaerobic digestion process at lab scale: Implication for biogas production. Bioresource Technol 192: 660-669. https://doi.org/10.1016/j.biortech.2015.06.022

8. Wedwitschka H, Jenson E, Liebetrau J (2016) Feedstock characterization and suitability assessment for dry anaerobic batch digestion. Chem Eng Technol 39 (4): 665-672. https://doi.org/10.1002/ceat.201500413

9. APHA. Standard Methods for the examination of water and wastewater. American Public Health Association, American Water Works Association, Water Environmental Federation, 22th ed. Washington.2012

10. Zou SZ, Wang XJ, Chen YL, Wan HW, Feng YZ (2016) Enhancement of biogas production in anaerobic co-digestion by ultrasonic pretreatment. Energ Convers Manage 112: 226-235. https://doi.org/10.1016/j.enconman.2015.12.087

11. Van Soest PJ, Robertson JB, Lewis BA (1991) Methods for dietary fiber, neutral detergent fiber, and nonstarch polysaccharides in relation to animal nutrition. $\mathbf{J}$ Dairy Sci 74: 3583-97. https://doi.org/10.3168/jds.S0022-0302(91)78551-2

12. Zhou CS, Yin J (1996) A method for measurement of TTC-dehydrogenase activity. Acta Scientiae Circumstantiae (in Chinese) 16:400-405. https://doi.or g/10.13671/j.hjkxxb.1996.04.004

13. Liu QQ, Pan SY, Long ZM, Li ZC, Du LQ (2020) Assessment of Fresh and Dry 
Rice Straw for Biogas Potential by Anaerobic Digestion. Bioenerg Res 13:845-852. https://doi.org/10.1007/s12155-020-10106-X

14. O'Rourke N, Psych R, Hatcher L (2013). A step-by-step approach to using SAS for factor analysis and structural equation modeling. SAS Institute.

15. Thaemngoen A, Saritpongteeraka K, Leu SY, Phuttaro C, Sawatdeenarunat C, Chaiprapat S (2020) Anaerobic digestion of napier grass (Pennisetum purpureum) in two-phase dry digestion system versus wet digestion system. Bioenerg Res 13: 853-865. https://doi.org/10.1007/s12155-020-10110-1

16. Mao CL, Feng YZ, Wang XJ, Ren GX (2015) Review on research achievements of biogas from anaerobic digestion. Renew Sust Energ Rev 45: 540-555. https://doi.org/10.1016/j.rser.2015.02.032

17. Li YY, Jin YY, Borrion A, Li HL, Li JH (2017) Effects of organic composition on mesophilic anaerobic digestion of food waste. Bioresource Technol 244: 213-224. https://doi.org/10.1016/j.biortech.2018.04.103

18. Liew LN, Shi J, Li Y (2011) Enhancing the solid-state anaerobic digestion of fallen leaves through simultaneous alkaline treatment. Bioresource Technol 102: 88288834. https://doi.org/10.1016/j.biortech.2011.07.005

19. Wahid R, Romero-Guiza M, Moset V, Moller HB, Fernandez B (2020) Improved anaerobic biodegradability of wheat straw, solid cattle manure and solid slaughterhouse by alkali, ultrasonic and alkali-ultrasonic pre-treatment. Environ Technol 41: 997-1006. https://doi.org/10.1080/09593330.2018.1516802

20. Boni MR, D'Amato E, Polettini A, Pomi R, Rossi A (2016) Effect of ultrasonication 
on anaerobic degradability of solid waste digestate. Waste Manage 48: 209-217. https://doi.org/10.1016/j.wasman.2015.10.031

21. Yao YQ, Chen SL (2016) A novel and simple approach to the good process performance of methane recovery from lignocellulosic biomass alone. Biotechnol Biofuels 9(1):1-9. https://doi.org/10.1186/s13068-016-0530-1

22. Capson-Tojo G, Trably E, Rouez M, Crest M, Steyer JP, Delgenes JP, Escudie R (2017) Dry anaerobic digestion of food waste and cardboard at different substrate loads, solid contents and co-digestion proportions. Bioresource Technol 233: 166175. https://doi.org/10.1016/j.biortech.2017.02.126

23. Zhang RR, Gu J, Wang XJ, Zhang L, Tuo XX, Guo AY (2018) Influence of combined sulfachloropyridazine sodium and zinc on enzyme activities and biogas production during anaerobic digestion of swine manure. Water Sci Technol 77 (11): 2733-2741. https://doi.org/10.2166/wst.2018.186

24. Wang YZ, Ren GX, Zhang T, Zou SZ, Mao CL, Wang XJ (2017) Effect of magnetite powder on anaerobic co-digestion of pig manure and wheat straw. Waste Manage 66: 46-52. https://doi.org/10.1016/j.wasman.2017.04.031

25. Zou SZ, Kang D (2018) Influence of ultrasonic pretreatment on characteriza tion of anaerobic co-digestion of dairy manure and maize straw. Acta Scient iae Circumstantiae (in Chinese) 38: 2696-2704. https://doi.org/10.13671/j.hjkx xb.2018.0090

26. Momayez F, Karimi K, Horvath IS (2018) Enhancing ethanol and methane production from rice straw by pretreatment with liquid waste from biogas $p$ 
lant. Energ Convers Manage 178: 290-298. https://doi.org/10.1016/j.enconma n.2018.10.023

27. Oliva A, Tan LC, Papirio S, Esposito G, Lens PNL (2021) Effect of methanolorganosolv pretreatment on anaerobic digestion of lignocellulosic materials. Renew Energ 169: 1000-1012. https://doi.org/10.1016/j.renene.2020.12.095

28. Komilis DP, Ham RK (2003) The effect of lignin and sugars to the aerobic decomposition of solid wastes. Waste Manage 23:419-423. https://doi.org/10. 1016/S0956-053X(03)00062-X

29. Yao YQ, Zhou JY, An LZ, Kafle GK, Chen SL, Qiu L (2018) Role of soi 1 in improving process performance and methane yield of anaerobic digestio n with corn straw as substrate. Energy 151: 998-1006. https://doi.org/10.101 6/j.energy.2018.03.069

30. Lin L, Yang LC, Xu FQ, Michel FC, Li YB (2014) Comparison of solid-st ate anaerobic digestion and composting of yard trimmings with effluent fro m liquid anaerobic digestion. Bioresource Technol 169: 439-446. https://doi.o rg/10.1016/j.biortech.2014.07.007

31. Zhen GY, Lu XQ, Kobayashi T, Kumar G, Xu KQ (2016) Anaerobic co-digestion on improving methane production from mixed microalgae (Scenedesmus sp., Chlorella sp.) and food waste: Kinetic modeling and synergistic impact evaluation. Chem Eng J 299: 332-341. https://doi.org/10.1016/j.cej.2016.04.118

32. Li YY, Wang YQ, Yu ZH, Lu JX, Li DY, Wang GY, Li Y, Wu Y, Li SY, Xu FQ, Li GX, Gong XY (2018) Effect of inoculum and substrate/inoculum ratio on the 

performance and methanogenic archaeal community structure in solid state anaerobic co-digestion of tomato residues with dairy manure and corn stover. Waste Manage 81: 117-127. https://doi.org/10.1016/j.wasman.2018.09.042

33. Cordoba V, Fernandez M, Santalla E (2018) The effect of substrate/inoculum ratio on the kinetics of methane production in swine wastewater anaerobic digestion. 


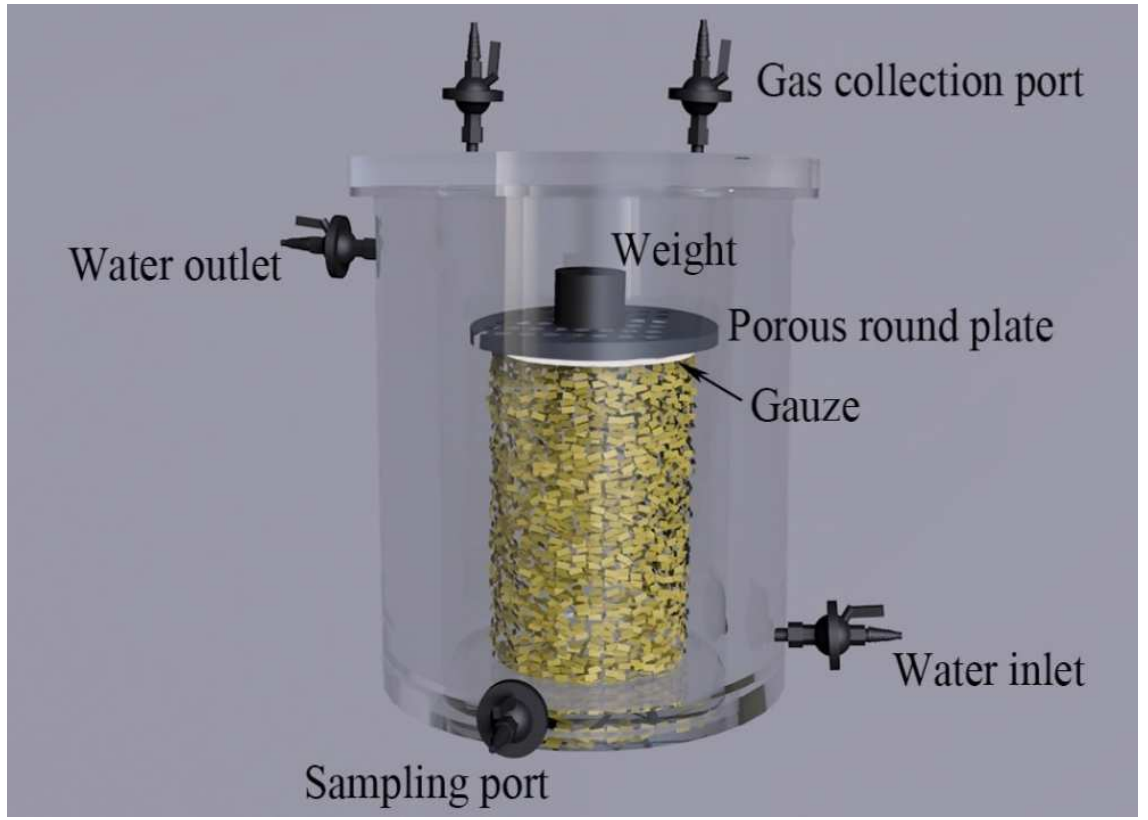

Fig. 1. The batch anaerobic digestion unit 

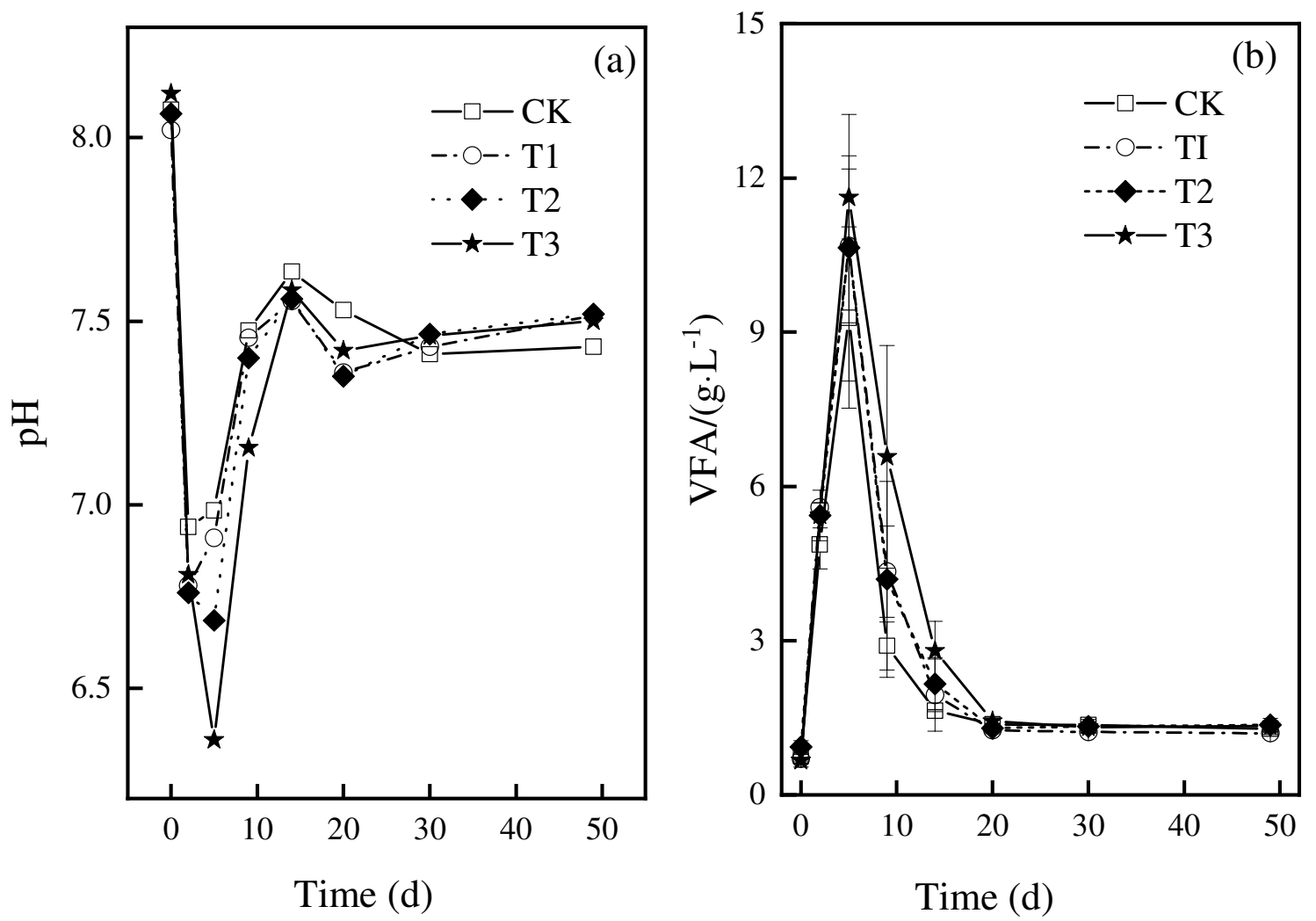

Fig. 2. Variation of $\mathrm{pH}$ value and VFA content of different external pressures during the biogas fermentation process. 

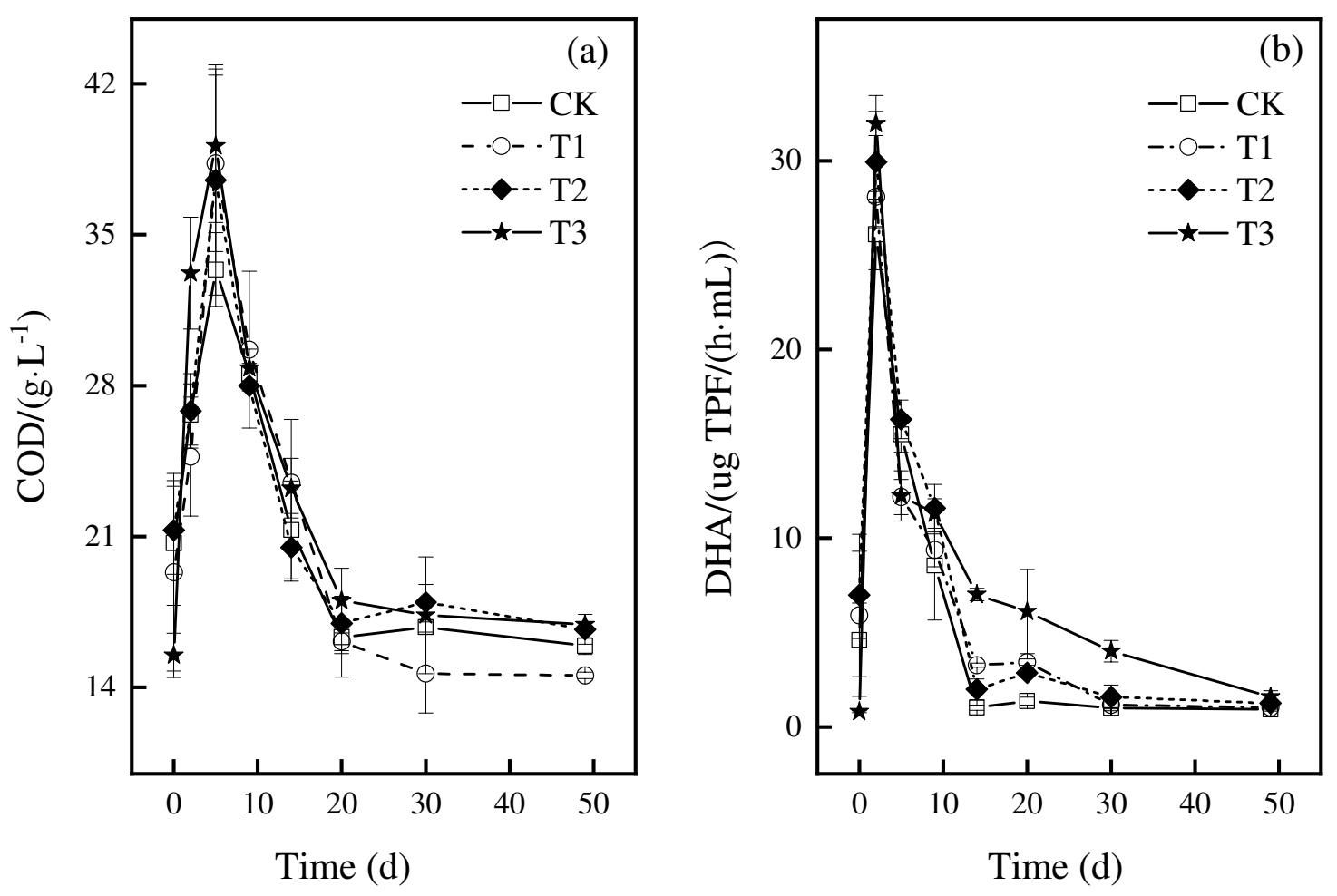

Fig. 3. Variation of COD and DHA concentration of different external pressures during biogas fermentation. 

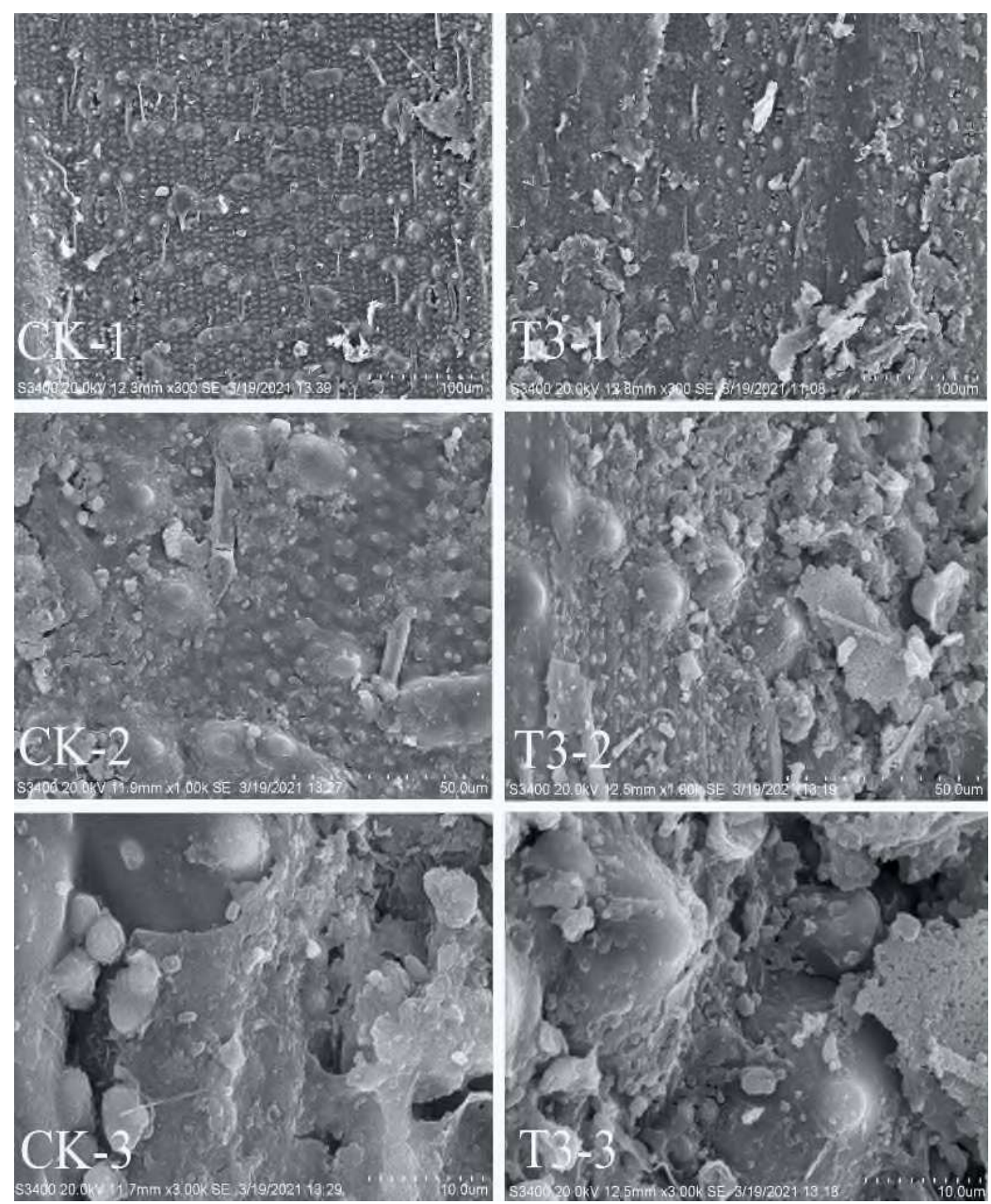

Fig. 4. Scanning electron micrographs of rice straw. CK: Untreated rice straw; T3: pressure was 2000 g. $1: \times 300 ; 2: \times 1000 ; 3: \times 3000$ 

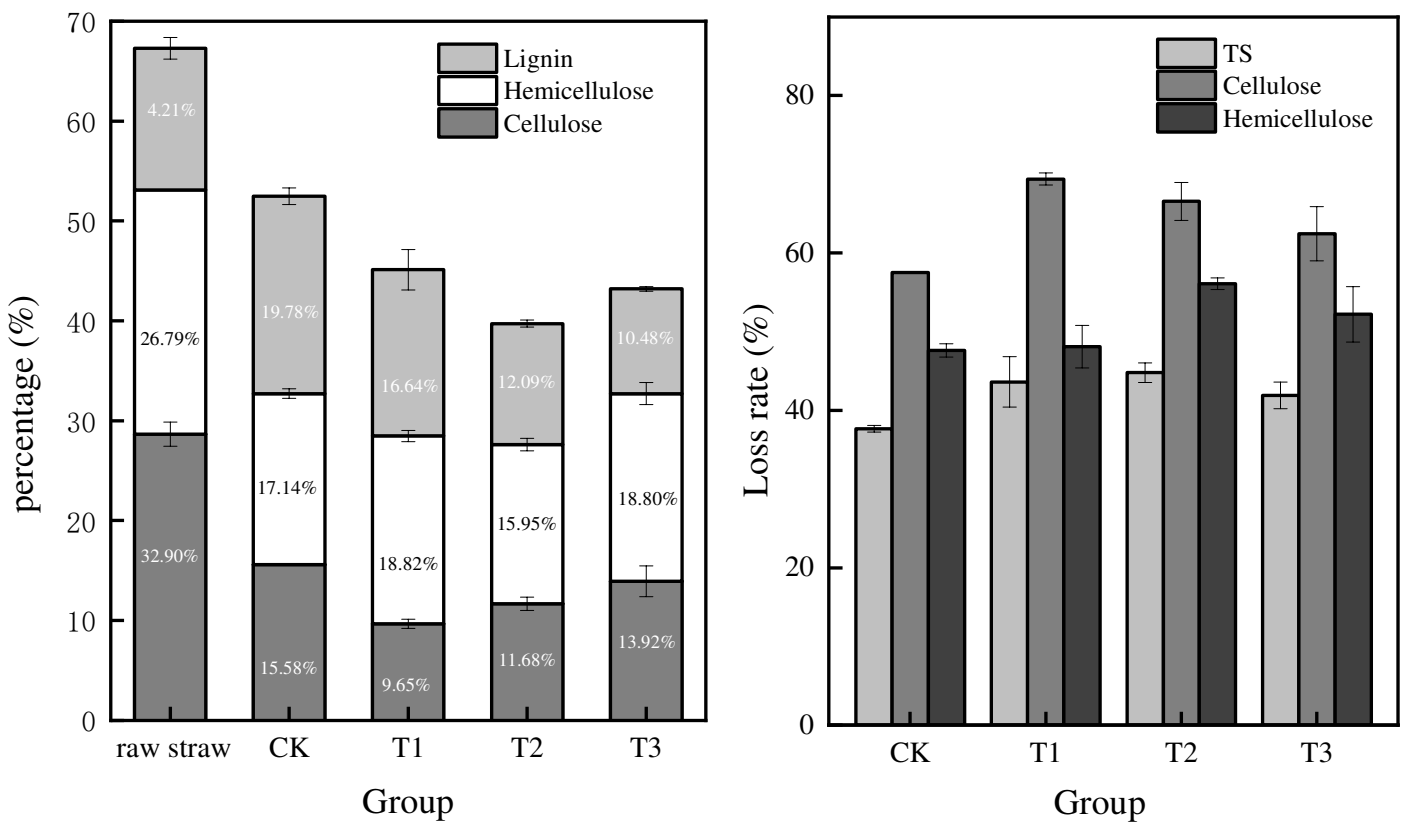

Fig. 5. The percentage lignocellulose content and the corresponding removal rate at the unused pressure 

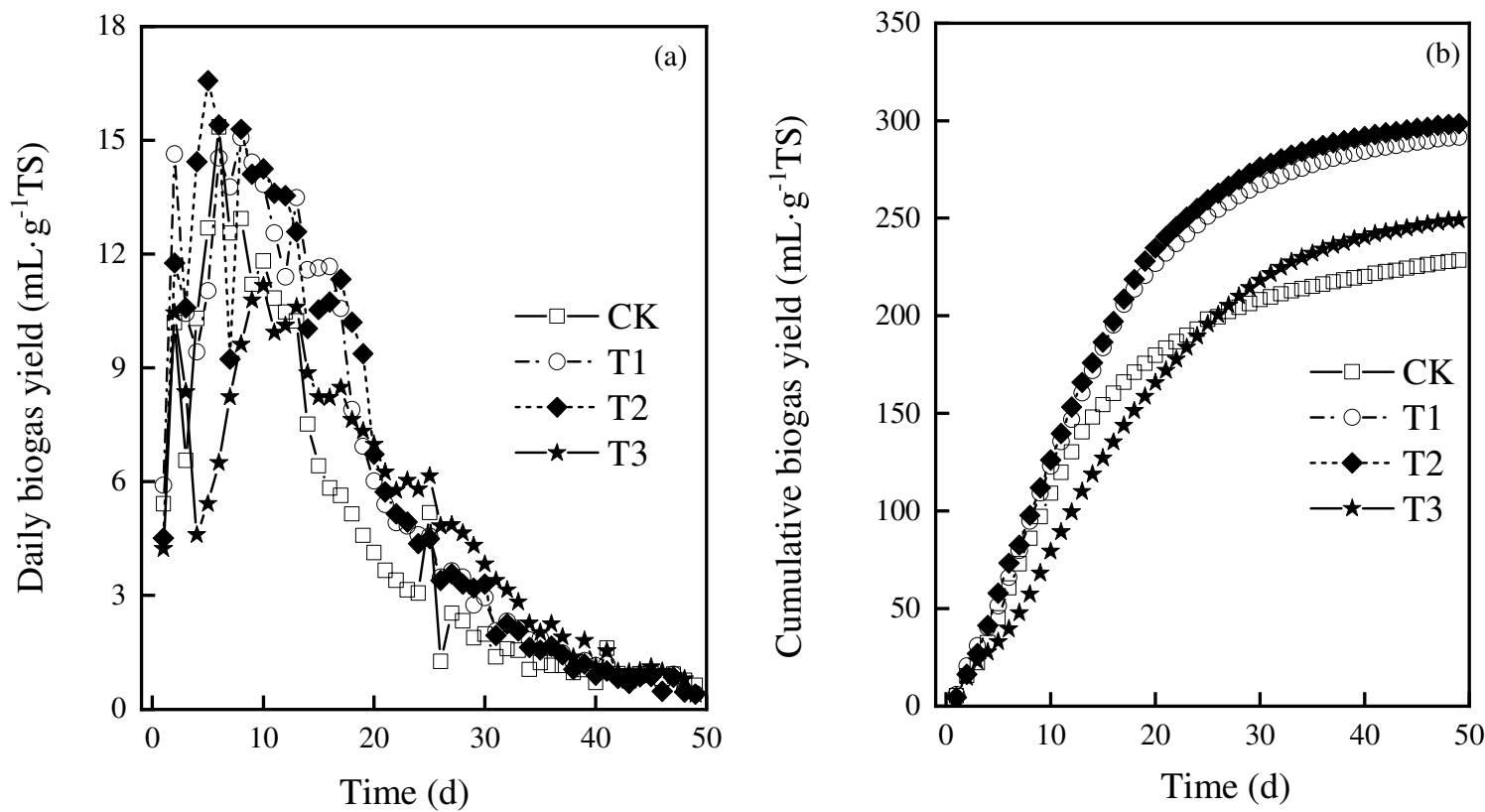

Fig. 6. Biogas production rate (a) and accumulative biogas yield (b) overtime under different external pressures. 
Table 1 Basic characteristic of fermentable substrates and inoculum

\begin{tabular}{ccccccccc}
\hline & $\mathrm{pH}$ & $\mathrm{TS}(\%)$ & $\mathrm{VS}(\%)$ & $\begin{array}{c}\text { Organic } \\
\text { carbon(\%) }\end{array}$ & $\begin{array}{c}\text { Organic } \\
\text { nitrogen }(\%)\end{array}$ & $\begin{array}{c}\text { Cellulose } \\
(\%)\end{array}$ & $\begin{array}{c}\text { Hemicellulose } \\
(\%)\end{array}$ & $\begin{array}{c}\text { Lignin } \\
(\%)\end{array}$ \\
\hline straw & - & 92.24 & 82.68 & 40.93 & 0.99 & 28.64 & 24.47 & 14.2 \\
inoculum & 7.35 & 2.85 & 47.22 & - & - & - & - & - \\
\hline
\end{tabular}


Table 2 Factor load matrix coefficients

\begin{tabular}{cccc}
\hline \multirow{2}{*}{ Reactors } & \multirow{2}{*}{ Indexes } & \multicolumn{2}{c}{ Loading } \\
\cline { 3 - 4 } & & Factor1 & Factor2 \\
\hline \multirow{4}{*}{ CK } & pH & -0.28 & -0.95 \\
& COD & 0.96 & 0.25 \\
& VFA & 0.76 & 0.56 \\
& DHA & 0.63 & 0.63 \\
\hline \hline \multirow{3}{*}{ T3 } & pH & -0.87 & -0.42 \\
& COD & 0.87 & 0.47 \\
& VFA & 0.97 & 0.21 \\
& DHA & 0.31 & 0.95 \\
\hline
\end{tabular}


Table 3 scores of factors.

\begin{tabular}{|c|c|c|c|c|c|c|c|c|c|c|c|}
\hline \multirow[b]{2}{*}{ Reactor } & \multirow{2}{*}{$\begin{array}{l}\text { Time } \\
\text { (Day) }\end{array}$} & \multicolumn{3}{|c|}{ Scores } & \multirow{2}{*}{$\begin{array}{l}\text { Overall } \\
\text { Ranking }\end{array}$} & \multirow[b]{2}{*}{ Reactor } & \multirow{2}{*}{$\begin{array}{l}\text { Time } \\
\text { (Day) }\end{array}$} & \multicolumn{3}{|c|}{ Scores } & \multirow{2}{*}{$\begin{array}{l}\text { Overall } \\
\text { Ranking }\end{array}$} \\
\hline & & $\begin{array}{c}\text { Facto } \\
\text { r1 }\end{array}$ & $\begin{array}{c}\text { Facto } \\
\text { r2 }\end{array}$ & $\begin{array}{l}\text { Compre } \\
\text { hensive }\end{array}$ & & & & $\begin{array}{c}\text { Facto } \\
\text { r1 }\end{array}$ & $\begin{array}{c}\text { Facto } \\
\text { r2 }\end{array}$ & $\begin{array}{l}\text { Compre } \\
\text { hensive }\end{array}$ & \\
\hline \multirow{8}{*}{ CK } & 0 & 0.39 & 1.73 & -0.58 & 8 & \multirow{8}{*}{$\mathrm{T} 3$} & 0 & 0.96 & 0.64 & -0.85 & 8 \\
\hline & 2 & 0.35 & 1.59 & 0.92 & 2 & & 2 & 0.10 & 2.41 & 0.77 & 2 \\
\hline & 5 & 1.65 & 0.73 & 1.23 & 1 & & 5 & 2.22 & 0.43 & 1.30 & 1 \\
\hline & 9 & 0.85 & 0.56 & 0.21 & 3 & & 9 & 0.59 & 0.04 & 0.37 & 3 \\
\hline & 14 & 0.11 & 0.66 & -0.37 & 4 & & 14 & 0.28 & 0.15 & -0.23 & 4 \\
\hline & 20 & 0.93 & 0.02 & -0.50 & 7 & & 20 & 0.53 & 0.14 & -0.39 & 5 \\
\hline & 30 & 1.05 & 0.30 & -0.43 & 5 & & 30 & 0.50 & 0.37 & -0.46 & 6 \\
\hline & 49 & 1.14 & 0.31 & -0.48 & 6 & & 49 & 0.44 & 0.64 & -0.51 & 7 \\
\hline
\end{tabular}




\section{Supplementary Files}

This is a list of supplementary files associated with this preprint. Click to download.

- Graphicalabstracts.docx 